\title{
Diurnal and Seasonal Variations of Rain Rate and Rain Attenuation on Ku-Band Satellite Systems in a Tropical Region: A Synthetic Storm Techniques Approach
}

\author{
Joseph S. Ojo1, Okeowo C. Rotimi² \\ ${ }^{1}$ Department of Physics, Federal University of Technology, Akure, Nigeria \\ ${ }^{2}$ Department of Physics, College of Education, Ikere-Ekiti, Nigeria \\ Email: josnno@yahoo.com
}

Received 13 February 2015; accepted 30 March 2015; published 31 March 2015

Copyright (C) 2015 by authors and Scientific Research Publishing Inc.

This work is licensed under the Creative Commons Attribution International License (CC BY). http://creativecommons.org/licenses/by/4.0/

(c) (i) Open Access

\section{Abstract}

In this paper, a time-varying rain characterization and diurnal variation in the Ku-band satellite systems simulated with synthetic storm techniques (SST) over a tropical location in Nigeria have been presented. Three years' rain rate time-series data measured by a raingauge located inside the Federal University of Technology Akure, Nigeria were utilized for the purpose of this work. The analysis is based on the CDF of one-minute rain rate; time-series simulated annual/seasonal and diurnal rain rate, rain attenuation statistics and fade margins observed over four time intervals: 00:00-06:00, 06:00-12:00, 12:00-18:00 and 18:00-24:00. In addition, comparison was also made between the synthesized values and rain attenuation statistics, at $12.245 \mathrm{GHz}$ for a hypothetical downlink from EUTELSAT W4/W7 satellite in the area. It could be observed that at $99.99 \%$ link availability, the fade margin as high as $\sim 20 \mathrm{~dB}$ may be required at Ku band uplink frequency bands in this area. We also observed that the communication downlinks working in the early morning and early to late in the evening hours must be compensated with an appropriate Down-Link Power Control (DLPC) for optimum performances during severe atmospheric influences in the region.

\section{Keywords}

Diurnal and Seasonal, Ku-Band Frequencies, TRODAN Data, Synthetic Storm Technique, Tropical Location 


\section{Introduction}

As the direct to home (dth) services continue to grow daily, nearly every home and offices are now connected to the Ku band satellite signal services. It provides satellite television programming directly to subscribers home anywhere in the country at Ku band frequencies $(12-18 \mathrm{GHz})$. Since it employs wireless technology, the television programs are transmitted to the subscriber's television directly from the satellite. This service does not involve the usage of cables and any other wiring infrastructures particularly between the antenna at the transmitting and receiving stations. However, at such higher frequency bands and direct transmission from satellite, signals received are strongly affected by rain in terms of fading and depolarization. Signal degradation by rain at frequencies above $10 \mathrm{GHz}$ cannot be ignored as widely reported [1] [2]. Satellite signals traversing through the atmosphere often lost part of the signal when encountered by hydrometeors most especially rain as a result of scattering and absorption of the electromagnetic energy thereby causing communication links to be unavailable for a certain period of time. The Ku-band broadcasting services in particular are affected by link outage especially during the critical transmission period such as real-time news, sport events and relaxation period when enjoying movies. Therefore, to achieve successful planning, designing and operations of the slant path and satellite communication systems, it is of importance to know the duration of rain fade, the time of day when it is likely to occur, and how frequently it happens [3] [4].

Several efforts have been made by many researchers to estimate the level of degradation of terrestrial and satellite signals in Nigeria based on ITU models [1] [5]-[8]. However, most of the investigations are based on the cumulative distribution of rain-induced attenuation while very limited investigations have been focused on fade dynamics of rain attenuation statistics. This work investigates such crucial statistics in a heavy rain region of tropical climate by exploiting a powerful and accurate tool that can produce all the necessary statistics of rain attenuation based on the time series of rain rate $R(\mathrm{~mm} / \mathrm{h})$ at the site, at any frequency and polarization [9] [10]. Such kind of tool often referred to as the Synthetic Storm Techniques (SST) has been identified and tested by investigators [10] [11].

In the recent times, due to lack of experimental data for rain attenuation for most locations in the tropical and subtropical region, the SST has been identified to be a powerful and accurate tool that can produce the necessary statistics of rain attenuation based on the time series of rain rate $R(\mathrm{~mm} / \mathrm{h})$ at the site, at any frequency and polarization, and for any slant path above about $10^{\circ}$ whenever a real radio link is not available [10] [12]. In addition, validity of the SST model has been presented in terms of yearly cumulative distribution in the work of [10] [13] and based on event wise as in [13] [14].

This work tends to provide reliable attenuation time-series of Ku band signals on a hypothetical satellite down link towards the Intelsat W4/W7-36B Satellite (Geostationary at $36^{\circ} \mathrm{E}$ ) en-route the study area based on SST by exploiting the rainfall rate time series measured in Akure, Nigeria (of the ongoing measurement on the Tropospheric Data Acquisition Network-TRODAN data). We also made an attempt to test the validity of the result obtained based on the experimental data collected in the same region. Results from the present will be needed for the proposed satellite in Nigeria (NIGCOMSAT-2).

\section{Study Location, Data and Measurement}

The study location is Akure (Lat: $7.17^{\circ} \mathrm{N}$, Long: $5.18^{\circ} \mathrm{E}$, Alt: $358 \mathrm{~m}$ ). The location belongs to a hot and humid area, influenced by rain-bearing southwest monsoon winds from the ocean and dry northwest winds from the Sahara Desert. The rainy season in this region lasts from April to October, with rainfall of about $1524 \mathrm{~mm}$ per year. Temperatures vary from $28^{\circ} \mathrm{C}$ to $31^{\circ} \mathrm{C}$ with mean annual relative humidity of about $80 \%$. The city belongs to the rain forest region located along the South western part of Nigeria. Due to the high temperature and relative high humidity, it is unarguably regarded as sunshine state of the nation Nigeria. The study, therefore attempts to establish local first order statistical rain attenuation using SST to mitigate the severe fade experienced at higher frequency bands because of the unpredictable weather condition experienced in this region.

Three years (2010-2012) rain rate data were processed to obtain needed data of one minute integration time from the TRODAN data. The most widely used method of data acquisition by TRODAN is via a network of rain gauges. Rain gauges used are standard $127 \mathrm{~mm}$ which stands $146 \mathrm{~mm}$ high in accordance with the World Meteorological Organization (WMO) standard. The gauge has an accuracy of $\pm 1 \%$ with the measuring range of a minimum of $2 \mathrm{~mm} / \mathrm{h}$ to a maximum of $400 \mathrm{~mm} / \mathrm{h}$. The data logger samples the data in every 10 seconds and averaged the data at every 1-minute. The Automatic Gain Control (AGC) voltage of each channel is sampled con- 
tinuously and stored in digital mode, with the date and time of each tipping of the rain gauge. The availability of the rain gauge in a year is about $99.5 \%$. The 0.5 of unavailability of the equipment is due to calibration and battery failure of the solar panel. The calibration of the rain gauge is maintained by regularly cleaning the capillarity. The reliability of the data from the gauge has to be ensured by regularly, keeping it clean, so that dust particles do not obstruct the free flow of water. Other detailed measurement methodology in the present study is available in [15]. Figure 1 presents the observatory garden for the measurement.

The one-minute time-series rain rate data generated are then used to estimate attenuation time series statistics based on the SST method of converting rain rate/time profiles recorded at a point to rain distance profiles with the aid of the translational velocity of the rain pattern that is estimated as the wind speed [16] [17].

\subsection{Synthetic Storm Techniques}

One of the major advantages of the synthetic storm techniques is the ability to employ local time series based on the assumption of dual-layer representation of precipitation to include the additional attenuation attributable to the melting layer. It has been reported that SST can estimate multivariate probability distributions of rain attenuation simultaneously exceeded in distant sites. This information is useful to design satellite systems with common on-board resources [18] [19]. The value of rainfall as a function of the length where rain moved on the line due to the wind direction with particular speed can as well be described using SST method. The application of the SST is also known to depend on some assumptions namely: the advection velocity of rain cell is assumed constant and must be in the direction of the projection of the link on the ground [9]. Other input parameters required by the SST model include: a) the altitude of the station above sea level, b) height of precipitation above sea-level, c) thickness of the melting layer and d) the elevation angle of the satellite. Detailed physical and mathematical fundamental are described at length by [13] [20] and therefore not reiterated here.

In addition, an average storm speeds, $v=3.46 \mathrm{~m} / \mathrm{s}$ obtained from the experimental site has been used in the computation. The vertical structure of the precipitation medium has been modeled with two layers of different depths, layer $A$ starts from the ground with the existence of rain (raindrops with a water temperature of $20^{\circ} \mathrm{C}$ ) and layer $B$ with melting hydrometeors at $0^{\circ} \mathrm{C}$ [21] as presented in Figure 2. $R_{A}$ is the homogeneously falling rain at layer $A$, while $R_{B}$ is the apparent rain rate of layer $B$ dominated by ice, where:

$$
R_{A}=r R_{B} \quad \text { with } r=3.134 \text {. }
$$

The input parameters needed by the SST model in this region are considered as follows. The altitude above sea level of the earth station is $H_{S}=0.358 \mathrm{~km}$. The parameters, necessary to relate the rainfall rate to the specific rain attenuation $(\mathrm{dB} / \mathrm{km})$ are as calculated from [21]. According to [22] the height of the precipitation (rain and melting layer) above sea level, $H_{B}$ depends on the latitude ( $\phi$ ) of the Earth station and can be expressed as:

$$
\begin{aligned}
& H_{B}=5 \quad \phi<23^{\circ} ; \\
& H_{B}=5-0.075\left(\phi-23^{\circ}\right) \quad \phi>23^{\circ} .
\end{aligned}
$$

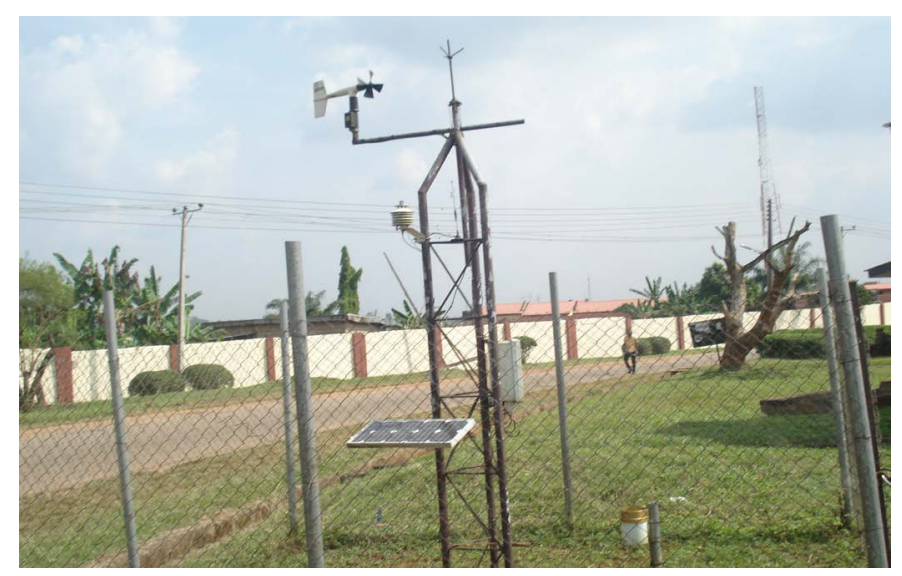

Figure 1. TRODAN observatory at FUT, Akure, Nigeria. 


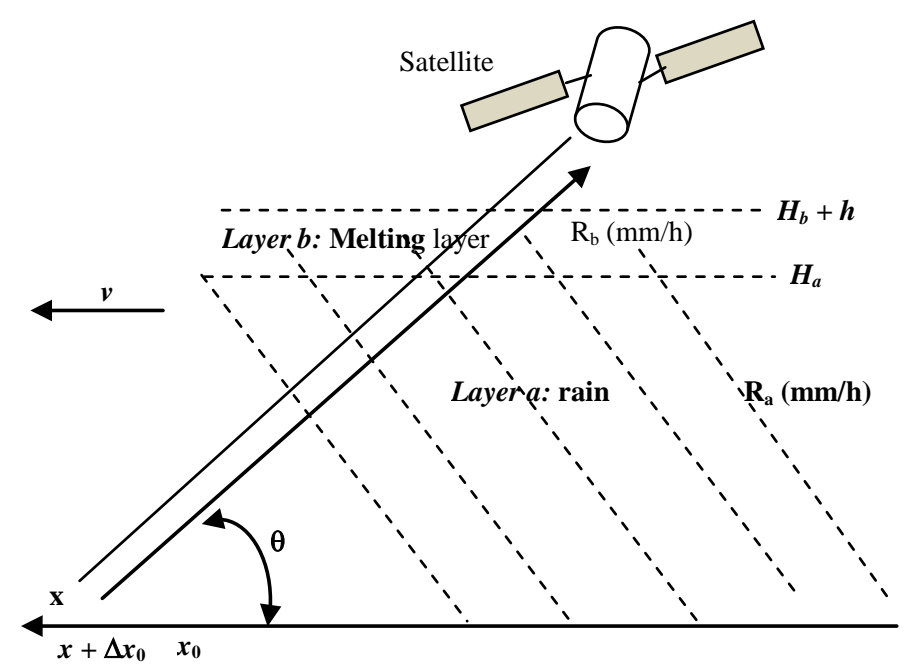

Figure 2. Schematic diagram of rain structure for synthetic storm techniques.

Based on the simulation, $H_{B}=3.8128 \mathrm{~km}$. Also, the thickness of the melting layer $(h)$ is considered to be 0.4 $\mathrm{km}$ regardless of the latitude [11]. The EUTELSAT W4/W7-36B Satellite (Geostationary at $36^{\circ} \mathrm{E}$ ) with its service footprint links at an elevation angle of $53.2^{\circ}$ is assumed for this work.

Hence the specific attenuation at a given point is converted into signal attenuation $\left(A\left(x_{0}\right)\right)$ for a satellite path using the following expression [20]:

$$
A\left(x_{0}\right)=k_{A} \int_{0}^{L_{A}} R^{\alpha A}\left(x_{0}+\Delta x_{0}, \xi\right) \mathrm{d} \xi+k_{B} r^{\alpha B} \int_{L_{A}}^{L_{B}} R^{\alpha B}\left(x_{0}, \xi\right) \mathrm{d} \xi
$$

where $\xi$ is the distance measured along the satellite path, $\Delta x_{0}$ is a shifting parameter that accounts for the fact that the radio path exists layer $B$ at $x_{0}+\Delta x_{0}$ and can be expressed as [14]:

$$
\Delta x_{0}=\Delta L \cos (\theta)=\frac{h}{\tan (\theta)}
$$

and

$$
\Delta L=L_{B}-L_{A}=\frac{h}{\sin (\theta)}
$$

where $\theta$ is the link elevation angle.

The height above sea level, $H_{A}$, of the upper limit of layer $A$ is also given as [11]:

$$
H_{A}=H_{B}-h=3.4128 \mathrm{~km} .
$$

We also assumed that the layers with liquid rain drops are at $20^{\circ} \mathrm{C}$, which is the average temperature for which most rain event occurs and the ice are at $0^{\circ} \mathrm{C}$ as earlier reported by [23]. The values of the $k$ and $\alpha$ presented in Table 1 have been scaled to account for the link elevation using the expressions provided in recommendation [21] [22], which combine the coefficients derived from horizontal and vertical polarizations.

Hence, the time-series attenuation is derived based on the above expressions by applying the Fourier transforms theory and taking into consideration some of the aforementioned assumptions.

\subsection{Propagation Experimental Data}

Propagation measurements over an earth-space path have been carried out in the year 2012 at the Department of Physics, Federal University of Technology Akure, Nigeria. The Ku-band modulated signal horizontally polarized at a frequency of $12.245 \mathrm{GHz}$ level has been received by a $60 \mathrm{~cm}$ offset parabolic dish, at an elevation angle 
of $53.2^{\circ}$. A SATLINK meter was used to receive Intermediate Frequency (IF: $950 \mathrm{kHz}$ to $2150 \mathrm{kHz}$ ) signals from a Low Noise Block (LNB) connected to the dish. The dish receives signals from the EUTELSAT W4/W7 satellite at an orbital location of $036.0^{\circ} \mathrm{E}$ longitude. The IF is fed into a spectrum analyzer, decoder and a computer. The spectrum analyzer was used to record samples of viewed spectrum over finite periods of time. The average power of the received IF signal at $1.153 \mathrm{GHz}$ was $-80 \mathrm{dBmV}$ during clear sky conditions. This was taken as reference power level to determine the extent of rain attenuation during a rainy event. The data of the received signal and the rainfall amount are sampled at every $1 \mathrm{~min}$. This setup is then used for estimation of the rain-induced attenuation on the satellite downlink during the rainfall events. Other detailed characteristics can be obtained from [24].

\section{Results and Discussions}

\subsection{Average and Total Monthly Rainfall Accumulation}

The average monthly rainfall accumulation for the three years of measurement considered for this study is shown in Figure 3. It could be observed that the monthly rainfall is dependent on the effects of the movement of the Inter Tropical Discontinuity (ITD). Nigeria experiences two different seasons per year; the dry season spanning from November till around February/early March and wet season covering March to October of the year. During the wet season, and due to the prevalence of rain, the ITD moves across the country. The month of April is usually observed as the beginning of the rainy season, but rainfall does not become intense until June to October, so the months of April and May experience scattered rainfall patterns. Observation reveals that the site recorded maximum average monthly rainfall accumulation of $\sim 234 \mathrm{~mm}$ during the month of September. However, because of the movement of the ITD, there is continuous rainfall in this region, even during the dry season (though minimal).

From the analysis, it is therefore noticed that, the worst months are between June and September. This is very important for determining the quality objectives of telecommunication systems for this region.

\subsection{Cumulative Distribution of One-Minute Rain Rate}

Figure 4 presents the cumulative distribution of one-minute rain rate as observed in the location. The results are presented to access the relationship between ITU-R recommendations P. 837-5 [25] and the measured results. We observed a good fit between measured and ITU recommended values at higher time percentages with low

Table 1. Characteristics of the study location.

\begin{tabular}{|c|c|c|c|c|c|c|c|c|}
\hline Location & Latitude & Longitude & Altitude (m) & Annual mean rainfall (mm) & \multicolumn{2}{|c|}{ Frequency (12 GHz) } & \multicolumn{2}{|c|}{ Frequency (18 GHz) } \\
\hline \multirow{2}{*}{ Akure } & \multirow{2}{*}{7.17} & \multirow{2}{*}{5.18} & \multirow{2}{*}{358} & & $k$ & $\alpha$ & $k$ & $\alpha$ \\
\hline & & & & 1486 & 0.0235 & 1.1505 & 0.0739 & 1.0412 \\
\hline
\end{tabular}

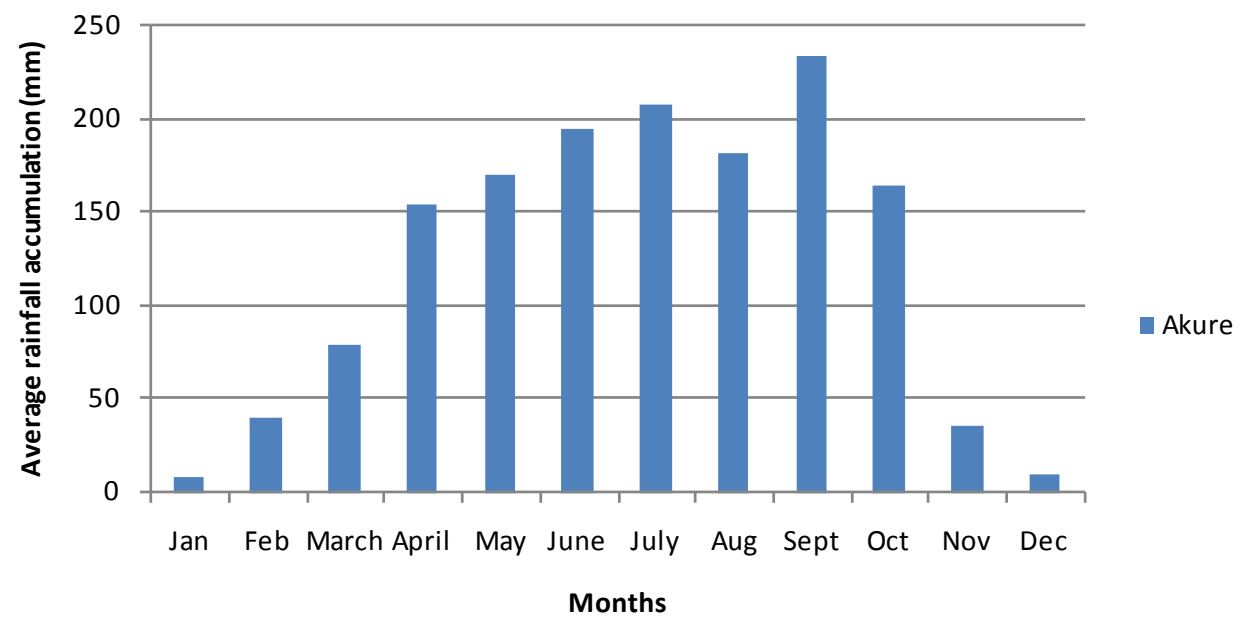

Figure 3. Monthly average of rainfall accumulations for the three years of measurement. 
rain rates (lower than $20 \mathrm{~mm} / \mathrm{h}$ ). However, considerable differences between the measured data and the ITU-R values are obtained at lower time percentages with large rain rates (greater than $50 \mathrm{~mm} / \mathrm{h}$ ). The estimate for the measured rainfall rate exceeded at $0.01 \%$ of the time is about $102 \mathrm{~mm} / \mathrm{h}$ while the equivalent estimate for the same time percentage is about $64 \mathrm{~mm} / \mathrm{hr}$ for ITU-R model. This yields a relative error of about $-40 \%$ based on ITU. P 311-12 [26].

The point rain rate estimate for Akure is not in sharp disagreement with those obtained over other tropical locations. For example, a similar result is presented in [27] for Brazil where the rainfall rates exceeded for $0.01 \%$ of the total time at Rio de Janeiro is around $118 \mathrm{~mm} / \mathrm{h}$. Estimates over locations in Malaysia also indicate that the $0.01 \%$ rain rate is around $120 \mathrm{~mm} / \mathrm{h}$ [28].

\subsection{Diurnal Variation of Rain Rate}

Figure 5 presents the diurnal rain patterns of the experimental site while the average rain duration is presented in Figure 6. We have categorized the duration over 24-hour with four time intervals (00-06, 06-12, $\cdots, 18-24)$. The total rain duration is obtained by dividing year of observation (3-year) to arrive at the relative distribution of rain duration in a year. The result shows that the probability of rain occurrence as well as rain intensity differs from time to time. In fact, the local climatology of the location is a major factor to be considered in determining rain formation. For example, Akure with an average annual precipitation amount of about $1486 \mathrm{~mm}$ and located in the rain forest zone of the country observed that rainfall is relatively less in the afternoon hours; around 06 to 2 PM local time (06:00-14:00 GMT) than in the evening hours. This may not be a general case for the whole country and some other tropical locations. As a matter of fact, [11] reported that maximum rain occur at afternoon over Indian land mass; the reverse is the case in our study where maximum rainfall occurs mostly during the evening times or early in the morning as a result of ITD movement.

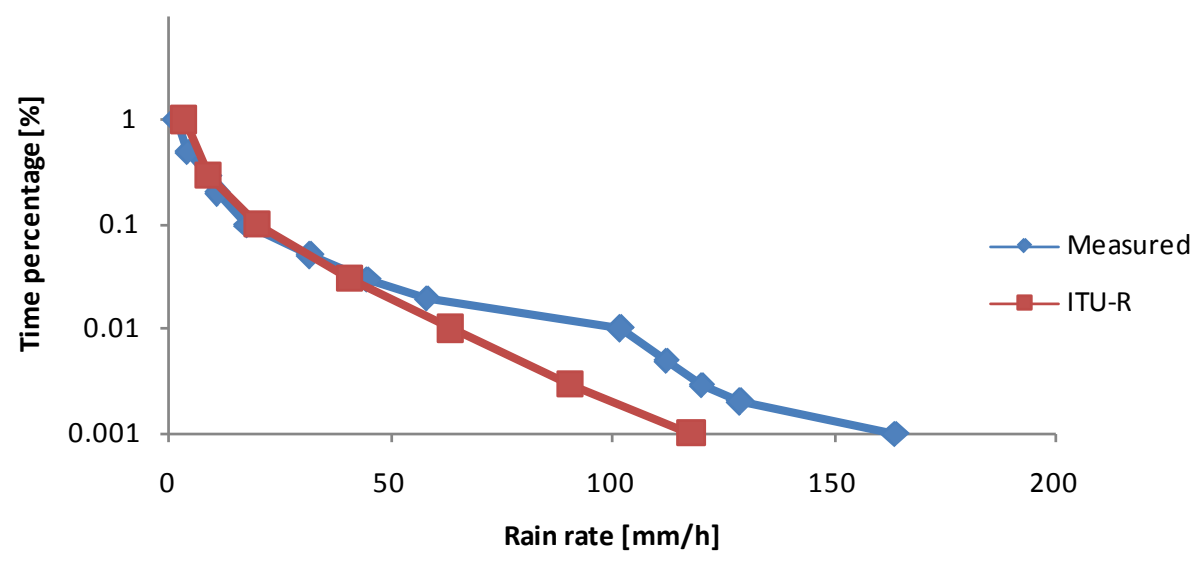

Figure 4. Cumulative distribution of rain rate.

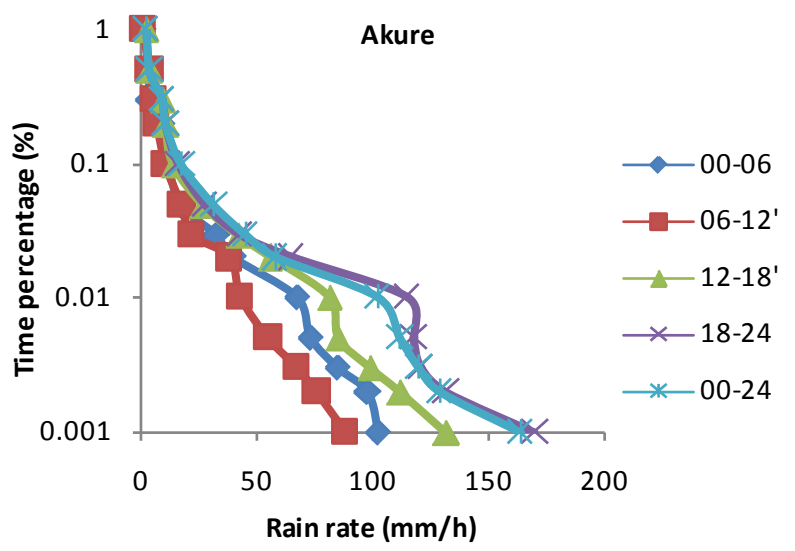

Figure 5. Cumulative distribution on a diurnal basis. 


\subsection{Model Validation Based on Ku-Band Propagation Experimental at $12.245 \mathrm{GHz}$}

For the purpose of validation of the rain attenuation obtained using the SST model, we have compared the result obtained with the result from the propagation experiment at the Federal University of Technology Akure, Nigeria as earlier discussed in Section 2.2. The comparison is presented in Figure 7.

The data presented in Figure 7 shows that the ITU recommendation overestimates the attenuation due to rain in Akure region. It is could also be seen that the SST model provides data very close to the measured attenuation. Although, the ITU values match well with both measured rain attenuation exceedances and the SST before $2 \mathrm{~dB}$ but later overestimated. Further observation based on prediction error shows that the synthesized attenuation show peaks lower than those in the measurements to about $-12 \%$ [26]. However, more years of propagation measurement will be needed to be certain of the level of the closeness between the predicted and the measured values of attenuation.

\subsection{Distribution of Annual Rain-Induced Attenuation}

Figure 8 presents the statistics of the annual rain attenuation estimated using SST at 12 and 18 GHz. For comparison, the ITU values based on the ITU-R 618-12 [29] model at the respective frequencies is also plotted. It is seen that the rain-induced attenuation obtained using SST model and the estimated attenuation values obtained using ITU model differ greatly at higher time percentages. As a matter of fact, the ITU model overestimates the attenuation due to rain in this location. This may be due to the fact the rain rate values as well as the $k$ and $\alpha$ coefficients used in the ITU model are not specific to the study location.

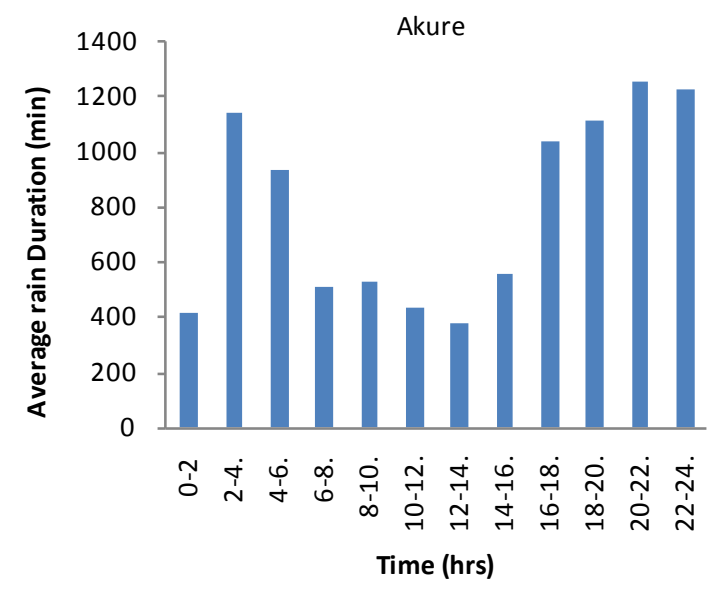

Figure 6. Average rain duration.

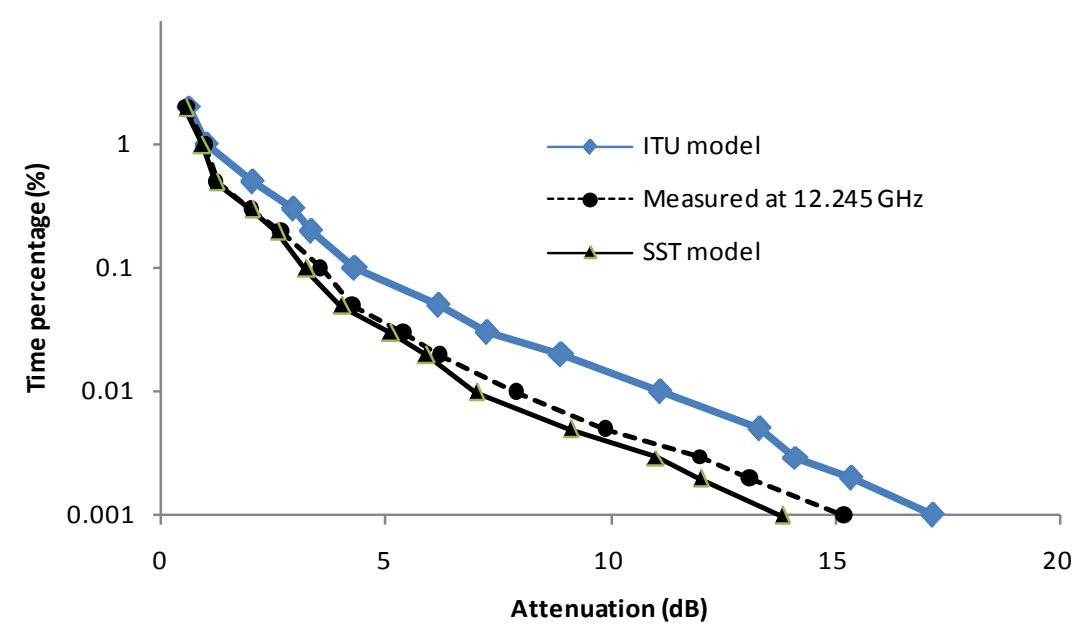

Figure 7. Comparison of measured rain attenuation at $12.245 \mathrm{GHz}$ with models. 


\subsection{Diurnal Influence on Rain-Induced Attenuation}

In Table 2, the typical diurnal variation of rain attenuation at $18 \mathrm{GHz}$ frequency over all the four daytime intervals considered are presented. It is seen that the required fade margin needed over the year differs at different availabality of time. For example at $99.9 \%$ availability of time which is equivalent to $0.1 \%$ signal unavailability, a relatively less fade margin of about $3.2 \mathrm{~dB}$ and $5.1 \mathrm{~dB}$ has to be implemented in the afternoon hours; around 06:00 to 12:00 noon and 12:00 to 18:00 local time respectively. However, higher fade margin > $20 \mathrm{~dB}$ may be needed during the late evening hours/night time and early morning hours (18:00 to 24:00 local time) at link availability of 99.99. This variation could be observed at downlink frequency of $12 \mathrm{GHz}$ considered although with different fade margin and at different link availabilities.

\section{Conclusion}

The variation of slant path Ku-band rain attenuation over a tropical location in Nigeria based on synthetic storm techniques has been presented. The measurement of rain rates over of the location has been carried out for three years period. Analysis of the average and total monthly accumulation shows that the worst months are between June and September. This is very important for determining the quality objectives of telecommunication system. Analysis of the statistics of annual rain-induced attenuation using SST up to about $20 \mathrm{~dB}$ fade margin may be required for $99.99 \%$ link availability at $18 \mathrm{GHz}$ frequency which may be too high for fade mitigation techniques' compensation over this region. The overall results will assist in proper communication system planning as well as reduce fade margin to very low value for better performances in this region.

\section{Acknowledgements}

We acknowledge the Centre for Atmospheric Research, National Space Research and Development Agency,

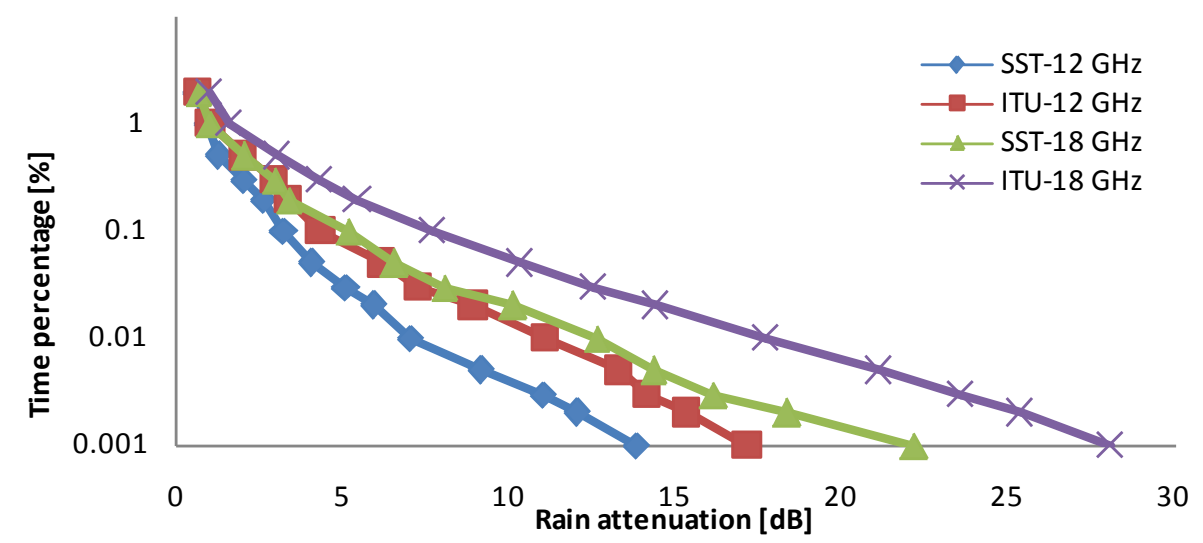

Figure 8. Rain Attenuation exceedance probability for different Ku-band down and uplink frequencies.

Table 2. Typical diurnal variation of fade margin to be implemented for specific daytime at $18 \mathrm{GHz}$.

\begin{tabular}{rrccccc}
\hline & Availability & $00: 00-06: 00$ & $06: 00-12: 00$ & $12: 00-18: 00$ & $18: 00-24: 00$ & Whole day \\
\hline Akure & $99.99 \%$ & 15.20 & 9.71 & 10.41 & $>20$ & 16.27 \\
$99.95 \%$ & 11.41 & 7.20 & 9.40 & 12.9 & 13.60 \\
$99.90 \%$ & 6.10 & 3.19 & 5.10 & 6.2 & 6.48 \\
$99.50 \%$ & 3.21 & 3.41 & 4.90 & 4.9 & 1.2 & 1.55 \\
$99.00 \%$ & 1.10 & 0.80 & 3.62 & 0.4 & 0.45 \\
$95.00 \%$ & 0.34 & 0.10 & 0.40 & 0.4 \\
\hline
\end{tabular}


Federal Ministry of Science and Technology, Anyigba, Nigeria and the Federal University of Technology Akure, Nigeria for the data used in this research.

\section{References}

[1] Ajayi, G.O., Feng, S., Radicella, S.M. and Reddy, B.M. (1996) Handbook on Radio Propagation Related to Satellite Communication in Tropical and Subtropical Countries. ICTP, Trieste, 7-14.

[2] Mandeep, J.S. (2011) Comparison of Rain Rate Models for Equatorial Climate in South East Asia. Geofizika, 28, 265274.

[3] Allnutt, J.E. and Haidara, F. (2000) Ku-Band Diurnal Fade Characteristics and Fade Event Duration Data from Three, Two-Year, Earth Space Radiometric Experiments in Equatorial Africa. International Journal of Satellite Communications, 18, 161-183. http://dx.doi.org/10.1002/1099-1247(200005/06)18:3<161::AID-SAT653>3.0.CO;2-\#

[4] Zhou, X.X., Lee, Y.H. and Teong, O.J. (2010) Effect of Diurnal Variations of Rainfall in Satellite Systems at Ku and Ka Band in Singapore. Asia Pacific Microwave Conference Proceedings, Yokohama, 7-10 December 2010, 19501953.

[5] Ajewole, M.O., Kolawole, L.B. and Ajayi, G.O. (1999) Theoretical Study of the Effect of Different Types of Tropical Rain Fall on Microwave and Millimetre-Wave Propagation. Radio Science, 34, 1103-1124. http://dx.doi.org/10.1029/1999RS900063

[6] Ojo, J.S., Ajewole, M.O. and Sarkar, S.K. (2008) Rain Rate and Rain Attenuation Prediction for Satellite Communication in Ku and Ka Bands over Nigeria. Progress in Electromagnetics Research B, 5, 207-223. http://dx.doi.org/10.2528/PIERB08021201

[7] Ojo, J.S., Ajewole, M.O. and Emiliani, L.D. (2009) One-Minute Rain Rate Contour Maps for Micro Wave-Communication System Planning in a Tropical Country Nigeria. IEEE Antennas and Propagation Magazine, 51, 82-89. http://dx.doi.org/10.1109/MAP.2009.5432046

[8] Ojo, J.S. and Omotosho, T.V. (2013) Comparison of 1-Min Rain Rate Derived from TRMM Satellite Data and Raingauge Data for Microwave Applications in Nigeria. Journal of Atmospheric and Solar-Terrestrial Physics, 102, 17-25. http://dx.doi.org/10.1016/j.jastp.2013.04.008

[9] Drufuca, G. (1974) Rain Attenuation Statistics for Frequencies above 10 GHz from Rain Gauge Observations. Journal of Geophysical Research: Atmospheres, 1-2, 399-411.

[10] Matricciani, E. (2008) Global Formulation of the Synthetic Storm Technique to Calculate Rain Attenuation Only from Rain Rate Probability Distributions. Antenna and Propagation Symposium, San Diego, 5-11 July 2008, 1-4. http://dx.doi.org/10.1109/APS.2008.4619006

[11] Das, S., Maitra, A. and Shukla, A.K. (2013) Diurnal Variation of Slant Path Ka-Band Rain Attenuation at Four Tropical Locations in India. Indian Journal of Radio and Space Physics, 42, 34-41.

[12] Ojo, J.S. and Owolawi, P.A. (2015) Application of Synthetic Storm Technique for Diurnal and Seasonal Variation of Slant Path Ka-Band Rain Attenuation Time Series over a Subtropical Location in South Africa. International Journal of Antennas and Propagation, 2015, Article ID: 474397. http://dx.doi.org/10.1155/2015/474397

[13] Matricciani, E., Riva, C. and Castanet, L. (2006) Performance of the Synthetic Storm Technique in a Low Elevation $5 \hat{\mathrm{A}}^{\circ}$ Slant Path at $44.5 \mathrm{GHz}$ in French PyrÃ@ñ̃@es. Proceedings of the First European Conference on Antennas and Propagation, Nice, 6-10 November 2006, 1-6. http://dx.doi.org/10.1109/EUCAP.2006.4584768

[14] Sanchez-Lago, I., Fontan, F.P., Marino, P. and Fiebig, U.C. (2007) Validation of the Synthetic Storm Technique as Part of a Time-Series Generator for Satellite Links. Antennas and Wireless Propagation Letters, 6, 372-375. http://dx.doi.org/10.1109/LAWP.2007.902810

[15] Ojo, J.S. and Falodun, S.E. (2012) NECOP Propagation Experiment: Rain-Rate Distributions Observations and Prediction Model Comparisons. International Journal of Antenna and Propagation, 2012, Article ID: 913596. http://dx.doi.org/10.1155/2012/913596

[16] Kheirallah, H.N., Segal, B. and Olsen, R.L. (1980) Application of Synthetic Storm Data to Evaluate Simpler Techniques for Predicting Rain Attenuation Statistics. Annales des Télécommunications, 35, 456-462.

[17] Das, D. and Maitra, A. (2014) Time Series Prediction of Rain Attenuation from Rain Rate Measurement Using Synthetic Storm Technique for a Tropical Location. AEU-International Journal of Electronics and Communications, 68, 33-36. http://dx.doi.org/10.1016/j.aeue.2013.07.008

[18] Matricciani, E. and Riva, C. (2005) The Search for the Most Reliable Long Term Rain Attenuation CDF of a Slant Path and the Impact on Prediction Models. IEEE Transactions on Antennas and Propagation, 53, 3075-3079.

http://dx.doi.org/10.1109/TAP.2005.854539

[19] Kanellopoulos, S.A., Panagopoulos, A.D., Matricciani, E. and Kanellopoulos, J.D. (2006) Annual and Diurnal Slant 
Path Rain Attenuation Statistics in Athens Obtained with the Synthetic Storm Technique. IEEE Transactions on Antennas and Propagation, 54, 2357-2363. http://dx.doi.org/10.1109/TAP.2006.879209

[20] Matricciani, E. (1996) Physical Mathematics Model of the Dynamics of Rain Attenuation Based on Rain Rate Time Series and a Two Layer Vertical Structure of Precipitation. Radio Science, 31, 281-291. http://dx.doi.org/10.1029/95RS03129

[21] ITU-R P.838-6 (2010) Specific Attenuation Model for Rain for Use in Prediction Methods. International Telecommunication Union, Geneva.

[22] ITU-R P.839-5 (2005) Characterizations of Precipitation for Propagation Modeling Rain Height Model for Prediction methods Recommendation P. ITU-R Ser., International Telecommunication Union, Geneva, 4.

[23] Maggiori, D. (1981) Computed Transmission through Rain in the 1-400 GHz Frequency Range for Spherical and Elliptical Drops and Any Polarization. Alta Frequenza (Italy), 50, 262-273.

[24] Obiyemi, O.O., Afullo, T.J.O. and Ibiyemi, T.S. (2013) Evaluation of Rain Degraded Digital Satellite Television Reception in Tropical Region. International Journal of Scientific \& Engineering Research, 4, 790-799.

[25] ITU-R P. 837-1, 2, 3, 4, 5 (2005) Characteristics of Precipitation for Propagation Modelling. Volume 1992-2003, P Series, International Telecommunication Union, Geneva.

[26] ITU-R P. 311-12 (2005) Acquisition, Presentation and Analysis of Data in Studies of Tropospheric Propagation. Recommendations.

[27] Pontes, M.S., Migliora, C.G.S. and Da Silva Mello, L.A.R. (1989) Preliminary Results of 12 GHz Radiometric Measurements in Brazil. Electronics Letters, 25, 76-77. http://dx.doi.org/10.1049/el:19890054

[28] Abdulrahman, A., et al. (2013) An Improved Slant Path Attenuation Prediction Method in Tropical Climates. Radioengineering, 22, 1082-1090.

[29] ITU-R P. 618-10 (2012) Propagation Data and Prediction Methods Required for the Design of Earth-Space Telecommunication Systems Recommendation P. ITU-R Ser., International Telecommunication Union, Geneva, 4. 